\title{
AMBIENTE HOSPITALAR SAUDÁVEL E SUSTENTÁVEL NA PERSPECTIVA ECOSSISTÊMICA: CONTRIBUIÇÕES DA ENFERMAGEM
}

Healthy and sustainable clinical environment in the ecossystemic perspective: contributions of the nursing area

Ambiente hospitalario saludable y sustentable en la perspectiva ecosistémica:

contribuciones de la enfermería

Jacqueline Sallete Dei Svaldi ${ }^{1}$

Hedi Crecencia Heckler de Siqueira²

\section{RESUMO}

Este texto propõe uma discussão sobre o ambiente hospitalar saudável e sustentável destacando-se as contribuições da enfermagem nesse processo. As bases filosóficas encontram-se ancoradas na teoria ecossistêmica que analisa as sensibilidades necessárias para entender a natureza e os elementos estruturantes do ambiente/espaço hospitalar. Enfatiza-se a força aglutinadora das Unidades Produtivas que, de maneira interdependente e inter-relacionada, devem buscar o espaço sustentável e saudável através da cooperação, flexibilidade e parceria dos elementos constituintes. Reitera-se que a realimentação constante do conhecimento, envolvendo de forma sistêmica todas as Unidades Produtivas, pode facilitar as atualizações necessárias para acompanhar as modificações e transformações do espaço e, assim, do próprio cosmos. Compreende-se que o profissional de enfermagem, ao favorecer a construção de inter-relações em um processo de interconexões, pode ser o agente de transformação e representar os nós conectivos que tecem a rede viva da organização do ambiente hospitalar, levando-o à sustentabilidade e a ser mais saudável.

palavras-chave: Ambiente de Instituições de Saúde. Ecossistema. Sistema de Saúde. Enfermagem.

\section{Resumen}

Se propone una reflexión del ambiente hospitalario saludable y sustentable destacando las contribuciones de la enfermería en este proceso. Las bases filosóficas se encuentran arraigadas en la teoría ecosistémica que analiza las sensibilidades necesarias para entender la naturaleza y los elementos de estructura del ambiente/espacio hospitalario. Enfatiza la fuerza aglutinadora de las Unidades Productivas que, de manera dependiente y relacionada entre si, deben buscar el espacio sustentable y saludable a través de la cooperación, flexibilidad y unión. Reitera el feedback constante del conocimiento, envolviendo sistémicamente todas las Unidades Productivas, puede posibilitar las actualizaciones necesarias para acompañar las transformaciones del espacio/cosmos. El profesional de enfermería, al favorecer la construcción de relaciones en un proceso de conexiones entre si puede ser el agente de la transformación y representar los nudos conectores que tejen la malla viva de la organización del ambiente hospitalario, lo llevando a la sustentabilidad y a ser más saludable.

palabras clave: Ambiente de Instituciones de Salud. Ecosistema. Sistemas de Salud. Enfermería.

\begin{abstract}
This discussion is about a healthy and sustainable hospital environment pointing out the nursing contributions in this process. The philosophical bases are anchored on the echo systemic theory which analyses the necessary sensibilities to understand nature and the structural elements of the hospital environment/space, and the joining forces of the Productive Unities by the cooperation, flexibility and partnership of the constituent elements. It is reaffirmed that the continuous feedback of the knowledge, involving in a systemic form all the Productive Unities, may favors the necessary up dates to accompany the modifications and transformations of the space and the cosmos itself. It is understood the nursing professional, when favoring the construction of interrelations in a process of interconnections can be the transforming agent and represent the connective knots which weave the net of the lively organization of the hospital environment, leading it to a more sustainable and more healthy one.
\end{abstract}

keywords: Health Facility. Environment. Ecosystem Health Systems. Nursing 


\section{INTRODUÇÃO}

0 trabalho nas instituições/organizações, na conjuntura do mundo globalizado com seus princípios de interligação, expansão acelerada desde o início do século XXI, exige de maneira significativa trabalhadores voltados para 0 conhecimento. As regras rígidas, predeterminadas, lineares ao cederem lugar para a flexibilização, a lealdade, a inteligência e, sobretudo, para a criatividade, podem iniciar um processo de uma nova ordem social capaz de propagar-se e tomar dimensões de instabilidade positiva e provocar a (re)organização sistêmica e, assim, produzir uma nova forma de pensar e agir institucional. A lealdade, a responsabilidade, a inteligência e a criatividade representam os maiores insumos das instituições/organizações do conhecimento porque são capazes de transformar, através de seus trabalhadores, o trabalho em relações de cooperação e parceria e, desta forma, instituir, por meio da educação/ aprendizagem, a estruturação de ambientes interdependentes, propícios para a propagação e fortalecimento da criatividade. ${ }^{1}$

Entende-se por ambiente hospitalar, na linguagem ecossistêmica, o lugar/espaço/território, no qual os trabalhadores da saúde, formados por diversas categorias, atendem as inúmeras necessidades de saúde dos usuários, os quais buscam, de forma individual ou coletiva, os serviços e ações nos níveis da promoção, prevenção e recuperação da saúde. Esse espaço é formado por um conjunto de elementos físicos e sociais interdependentes, ${ }^{2}$ integrados, interrelacionados, em que as redes humanas formam e constituem a cultura própria desse território em busca de ambientes mais harmoniosos, saudáveis e sustentáveis.

A sustentabilidade pode ser considerada uma nova forma de produzir sem trazer prejuízos ao espaço e nem aos seres humanos envolvidos no processo e, indiretamente, à sociedade em geral. Ela deve apoiar-se nos princípios da satisfação das necessidades do ser humano, e não simplesmente no poder econômico. Atualmente tem-se orientações ${ }^{3}$ que se baseiam na construção do aprendizado e na implementação de estruturas de tomada de decisão nas organizações para torná-las mais sustentáveis. Elas indicam os resultados a serem obtidos e apontam os meios para alcançar a maturidade organizacional. Entretanto, não orientam os processos a serem seguidos para alcançar a sustentabilidade.

A instituição/organização hospitalar vista como um sistema social dinâmico representa uma totalidade que, através de suas relações sociais, busca o apor te de parceria para a realização dos processos produtivos de forma integrada. Por ser de natureza dinâmica e complexa, ela precisa fundamentarse em um referencial que the permite realizar adequaç̃̃es e transformações, utilizando a competência, a intuição e a criatividade do ser humano que é capaz de estabelecer relações e dinamizar o espaço que ocupa. ${ }^{4}$ Assim, a sustentabilidade do ambiente ecossistêmico, ao apoiar-se nos princípios da interdependência, fluxo cíclico de recursos, cooperação, parceria, constrói-se sob diferentes aspectos de um mesmo padrão de organização, como os ecossistemas se organizam, para maximizar a sustentabilidade do espaço/lugar/território.

Esse referencial sistêmico norteador encontra-se apoiado em diversos autores ${ }^{1,4,5,6,7,8,9}$ e possui algumas características definidoras, tais como: interdependência, diversidade, parceria e reciclagem, que ao serem aplicadas, podem construir resultados benéficos e significantes, obtidos no coletivo. Além dessas características cita-se a flexibilidade que permite as adequações necessárias para introduzir as inovações no atendimento da complexidade e da dinamicidade resultante das inter-relações dos processos socioculturais na busca do equilíbrio - a sustentabilidade.

Há relevância da discussão a respeito do ambiente hospitalar saudável e sustentável, na perspectiva ecossistêmica, e a abordagem das contribuiç̧ões da enfermagem nesse processo encontra-se ancorada na complexidade ${ }^{5,9,10}$ e na importância que esses conceitos possuem na sua essência e o que são capazes de revelar nas inter-relações subjacentes das unidades constituintes da totalidade do espaço de forma criativa e inovadora para todo o sistema. A complexidade é entendida, neste contexto, pelos processos de interconexões, que favorecem o surgimento de novas estruturas. ${ }^{1}$

Considera-se que a reflexão poderá ser de expressivo valor a todo conjunto hospitalar ecossistêmico e, principalmente, para a enfermagem, pois, percebe-se, ainda que empiricamente, que esse grupo de trabalhadores no cotidiano do seu trabalho, não se apreende como o agente capaz de interferir positivamente na construção do seu próprio ambiente/espaço. Deste modo, não avalia o alcance do significado do seu próprio trabalho e sua capacidade intrínseca. A prática mostra que a enfermagem constrói um processo produtivo expressivo na área da saúde hospitalar, toma decisões coerentes e rápidas, conjuntamente com outros profissionais, ou, até mesmo, de forma independente, contribui de maneira significativa para a manutenção e a recuperação da vida, e, no desenvolvimento do processo produtivo, conhece, praticamente, todos os elementos constituintes do espaço hospitalar. Enfim, talvez seja necessário provocar na enfermagem a instabilidade/questionamentos para fazê-la perceber que é agente de ação, manutenção, construção e transformação do seu espaço/ambiente e que é capaz de produzir/lançar uma nova forma de pensar e agir. É importante fazê-la perceber que possui a energia/força/capacidade/poder de promover nos ambientes de trabalho o surgimento de novas e emergentes estratégias sistêmicas aos problemas que se apresentam e, consequentemente, de construir um ambiente saudável e sustentável. Nessa discussão, deve-se considerar que

As coisas a que as pessoas prestam atenção são determinadas pelo que essas pessoas são enquanto indivíduos e pelas características culturais de suas comunidades de prática. Não é a intensidade ou a 
frequência de uma mensagem que vai fazê-la ser ouvida por elas; é o fato de a mensagem ser ou não significativa para elas ${ }^{1: 123}$.

Com base no exposto, objetiva-se discutir sobre 0 ambiente hospitalar saudável e sustentável na perspectiva ecossistêmica e as contribuições da enfermagem nesse processo.

\section{AMBIENTE HOSPITALAR ECOSSISTÊMICO}

0 ambiente/espaço é um lugar construído pelos elementos físicos da natureza, que, através de processos particulares e individuais, inclusive com uma determinada conformação e regidos por padrões culturais específicos, originam a forma particular de viver aos seres que o ocupam. ${ }^{2}$ Essas características constituintes do espaço/ambiente de um lugar específico conduzem a apreender a importância que a cultura é capaz de exercer sobre a sua conformação. Ela, ao interpor-se entre os meios disponíveis ao ser humano, neste espaço, é capaz de modificá-lo e transformá-lo de tal maneira que se torna único, particular do grupo que o ocupa. ${ }^{2}$ Portando, a cultura de um ambiente hospitalar se expressa em uma dimensão social, pois é o resultado das formas encontradas, pelos diversos grupos que se ajustam nesse espaço, para satisfazer as suas necessidades.

Para entender 0 ambiente hospitalar, na perspectiva ecossistêmica, torna-se necessário considerá-lo como um sistema social dinâmico composto por uma diversidade de elementos, que se inserem, costituem a totalidade, se interrelacionam e, em conjunto, buscam alcançar a eficiência institucional desse espaço. Por conseguinte, o espaço/ambiente na dimensão ecossistêmica é um todo integrado constituído pelos aspectos físicos e sociais que se manifestam em constante interação e compõem os elementos estruturantes desse lugar. Esses podem ser concebidos como as Unidades Produtivas de trabalho/serviços. Essas unidades produtivas são os núcleos estruturantes de um hospital, compostas pelos elementos físicos: área física, equipamentos hospitalares, mobiliário, fluxogramas de processos de trabalho, metodologias, software e informática; e pelos elementos sociais: equipes multiprofissionais, conhecimento, informação e comunicação, que, de forma interdependente, se interrelacionam e constituem o todo da instituição/organização hospitalar e buscam produzir saúde.

Os profissionais da equipe multiprofissional, através do conhecimento específico, particular e singular, promovem a assistência à saúde de usuários que poderão ser do Sistema Único de Saúde (SUS), particulares e ou conveniados. Eles são os responsáveis pela operacionalização do processo produtivo e pela busca expressiva de resultados. Além da assistência que prestam aos usuários, ao tratar-se de um hospital universitário, são coadjuvantes do ensino, pesquisa e extensão que se processam nos seus ambientes. Assim, promovem a assistência à saúde, educam, produzem conhecimento e transformam realidades a partir da interface com os clientes internos e externos.

Na perspectiva ecossistêmica, cada Unidade Produtiva, em relação à totalidade, representa um sub-sistema do sistema maior. ${ }^{1,4,5,6}$ Cada sub-sistema é um microssistema, e o conjunto de microssistemas forma o meso e macrossistema. 0 conjunto de elementos, estruturantes dessa realidade, ao relacionar-se entre si, é capaz de construir verdadeiras redes no espaço/ ambiente em que co-habita e desenvolver-se de forma harmoniosa, saudável na busca pela sustentabilidade. Essas redes encontram-se unidas através de nós que the dão consistência, firmeza, estabilidade, segurança e podem ser considerados os elos conectivos ${ }^{4}$ que interligam os elementos constituintes das Unidades Produtivas que reforçam as relações entre elas.

\section{Ambiente hospitalar ecossistêmico saudável e sustentável}

Pensar, no momento, o ambiente hospitalar saudável e sustentável em uma concepção ecossistêmica é conceber o trabalhador, sua atuação na Unidade Produtiva e as interrelações que estabelece com a totalidade organizacional enquanto explora as possibilidades que o espaço lhe oferece para exercer o seu trabalho/atividade. Para realizar a sua atividade, faz valer-se de referenciais de outras disciplinas capazes de auxiliá-lo na elaboração e compreensão da realidade que vivencia.

Os trabalhadores, ao buscar a eficiência de sua Unidade Produtiva, precisam, de forma permanente, proceder a reciclagem da aprendizagem e promover nas relações pessoais e nos processos produtivos o feedback. Nas relações pessoais, é essencial o cultivo e o fortalecimento dos valores dos seres humanos, entre os quais, o respeito, a gentileza, a amorosidade, a humanidade, o desvelo e a justiça. Portanto, construir um espaço saudável requer ter como objetivo principal valorizar a vivência de cada momento, respeitar a diversidade, disseminar alegria, prazer e desejar a realização pessoal e profissional de todos. Quanto aos aspectos físicos ou materiais, é importante que não existam resíduos, tudo deve ser aproveitado na busca da sustentabilidade ${ }^{13}$ a ser alcançado através do esforço no coletivo. ${ }^{4}$ Assim, a reciclagem deve envolver o controle, 0 desperdício, a área física e a forma correta de uso de todos os materiais e equipamentos necessários, para realizar a assistência/cuidado ao cliente, considerados coadjuvantes na manutenção da vida. 0 uso inadequado pode comprometer a ação positiva da assistência/cuidado.

Flexibilidade é a capacidade, a competência de recuperar o equilíbrio do sistema em momentos de turbulência ocasionada por alguma variável inadequada e que provocou a desestabilização do sistema. ${ }^{1,5}$ Para a enfermagem, essa característica pode tornar-se significativa, pois os profissionais 
são numerosos nos ambientes e pela característica da profissão nem sempre existe flexibilidade para entender as necessidades de cada um do grupo, e isso, muitas vezes, pode causar conflitos extremos. Os conflitos podem provocar, na convivência do conjunto, desde a agressividade até a apatia e desinteresse pela busca da eficiência. Os conflitos necessitam ser tratados cuidadosamente para que se encontre o equilíbrio e, assim, se ofereça às pessoas um ambiente harmonioso e saudável. ${ }^{12}$ Acredita-se que esta característica, ao ser utilizada, poderá alavancar nos ambientes um clima harmônico e produzir um espaço de vivência e trabalho saudável.

A diversidade manifesta-se de maneira constante no ambiente hospitalar, tanto na constituição da multiplicidade de grupos profissionais que nela exercem as suas atividades profissionais como pelos inúmeros meios e estratégias utilizadas para alcançar os propósitos que a instituição/organização se propõe. Torna-se necessário buscar entender essa complexidade ${ }^{5,9,10}$ existente nos ambientes de atenção hospitalar para que sejam encontradas soluções mais rápidas e satisfatórias aos problemas que se apresentam nas relações internas e externas à instituição/organização.

Grande parte dos profissionais que trabalham nas instituições/organizações hospitalares desconhece ou não utiliza as experiências advindas da diversidade para enriquecer o seu conhecimento através da construção coletiva a qual permite encontrar na diversidade soluções criativas e inovadoras. A composição de determinado sistema, através da significativa diversidade de pessoas, pensamentos, instrumentos, fluxogramas, metodologias, técnicas e tecnologias, possibilita encontrar soluções emergentes aos problemas detectados, que, muitas vezes, com menor dispêndio de insumos torna o ambiente sustentável e mais saudável. Enfim, é recomendável valerse do conceito chave, definidor do trabalho da enfermagem, o 'cuidado', pois traz no seu conjunto o planejar, executar, verificar, educar corrigir, mudar e transformar, positivamente, as vivências e os ambientes.

A concepção sistêmica é capaz de aumentar a dinamicidade do espaço hospitalar como um todo, pois

o que pode ser proposto dentro de uma concepção sistêmica é a dinâmica do sistema e a forma de melhorá-la como um todo, levando em consideração o contexto sócio-econômico-político da sociedade na qual a organização se encontra. É preciso manter a coerência com a sociedade porque ela éformada por seres humanos, que possuem histórias próprias, diferentes, individuais, complexas, contendo uma força intrínseca, com capacidade de grandes transformações que, habilmente, conscientizadas criticamente, tornam-se capazes de construir ideias, modificá-las, reconstruindo-as de forma constante, conforme as necessidades e as exigências da coletividade" $4: 88$.

Assim, ao serem consideradas as características de sustentabilidade, as necessidades do conjunto da enfermagem e a sua capacidade construtiva de ideias, é possível promover verdadeiras redes vivas no espaço/ambiente em que co-habita, desenvolvendo um clima no ambiente de trabalho mais satisfatório, eficiente e, assim, de forma mais harmoniosa e saudável física, psíquica, social e espiritualmente, construir um produzir e viver melhor.

Reitera-se que o ser humano/trabalhador da área da saúde, em especial o da enfermagem, necessita buscar tecnologias que possam favorecer as relações no produzir e viver de forma sustentável/saudável em ambientes hospitalares por ser "um processo que permite satisfazer as necessidades [dos elementos e dos conjuntos nos ambientes sociais e, nestes, as hospitalares e culturais] da população atual sem comprometer a capacidade de atender as gerações futuras ". "0:19

\section{CONTRIBUIÇÕES DA ENFERMAGEM}

Quanto à profissão de enfermagem, verifica-se, em uma percepção empírica da realidade, que esta possui sua cultura enraizada no comando hierárquico e determinado, quanto ao modo de pensar, organizar e desenvolver o trabalho. ${ }^{14}$ Os enfermeiros são preparados desde a academia e, após, no mundo do trabalho, a aceitar o cumprimento de tarefas predeterminadas, em um modelo metodológico, preferentemente estático e inalterado de obediência.

Este modelo, produzido e reproduzido ao longo dos anos, geralmente na maioria das instituições de ensino e hospitalares, ao não ser questionado, traz consequências, em um primeiro momento, ao aprendizado do acadêmico de enfermagem, quanto ao que é poder e como implementar as relações de poder no mundo do trabalho. Este, como profissional, pode ter a sua saúde afetada tanto física como psíquica, social e até espiritual e, de maneira interdependente, também, atingir a eficiência produtiva e a sustentabilidade do ecossistema hospitalar. Então, ao considerar todas as relações produzidas no ecossistema hospitalar e os resultados alcançados, estes podem ser positivos ou não. Entretanto, é necessário considerar o resultado no seu conjunto porque o todo é maior do que a soma das partes. ${ }^{1,5,6}$ Para proceder a ruptura desse ciclo cultural, é necessária a conscientização dessa vivência determinística, recheada de submissão e obediência, que não satisfaz e deixa o profissional de enfermagem insatisfeito consigo mesmo e com o seu pensar e fazer. Deve haver o rompimento desse modelo, na sua raiz no questionamento, e dar-se conta do que está acontecendo para encontrar respostas criativas e inovadoras benéficas à enfermagem. ${ }^{4}$ 
Diante do exposto, e considerando os avanços do conhecimento, talvez seja o momento de arquitetar outra forma no produzir e viver para os profissionais da enfermagem para que esta se torne mais saudável e sustentável e, por conseguinte, aos demais profissionais das diversas unidades estruturantes da instituição hospitalar. Acredita-se nesta possibilidade, pois é dado ao ser humano e, portanto, aos profissionais de enfermagem, através das relações sociais e formação de redes vivas, a capacidade de pensar e encontrar novas formas de ser e de estar nos ambientes hospitalares, ${ }^{4}$ inspirando-se na estruturação dos ecossistemas naturais. Compreende-se, então, que no ambiente hospitalar, o profissional de enfermagem pode ser 0 agente de transformação da realidade vivenciada e, em um processo de interconexão e aprendizado imbricado, favorecer a construção do fazer dos demais trabalhadores ${ }^{4}$ desta forma, em um crescente e constante interagir, promover um círculo virtuoso benéfico, levando a sustentabilidade dos sistemas singulares e coletivos.

Ao considerar o profissional de enfermagem, no ambiente hospitalar, como um dos elementos constituintes da rede viva do ambiente e, que ao ser perturbado ${ }^{1}$ pode promover a comunicação e gerar criativamente significados no seu próprio conjunto/sistema é de se pensar, também, que este pode influenciar no aprendizado e liberdade na construção e reconstrução contínua de todos os demais trabalhadores ${ }^{4}$, nos seus processos produtivos, sub-sistemas, meso e macrossistemas. ${ }^{7}$ Então, por ter o profissional de enfermagem a capacidade de pensar, elaborar respostas aos problemas emergentes e agir criativamente na busca do equilíbrio, para si e para os demais conjuntos ${ }^{4}$, considera-se este o encontro da sua essência, o sentido da própria vida e vivência como trabalhador, que é o de produzir o bem comum de maneira constante no ambiente em que vive e trabalha. Esses conceitos encontram apoio em um pensador sistêmico ao afirmar

Quando as pessoas modificam as instruções que recebem, estão respondendo criativamente a uma perturbação, pois é nisso que reside a essência da vida. Com suas respostas criativas, as redes vivas dentro da organização geram e comunicam significados, afirmando a sua liberdade de recriarse continuamente. Até mesmo uma resposta passiva, ou de "agressividade passiva", é um modo pelo qual as pessoas manifestam sua criatividade. A obediência estrita só pode ser obtida à custa da vitalidade das pessoas, que são então transformadas em robôs indiferentes e apáticos ${ }^{1: 124}$.

0 ambiente hospitalar, para ser saudável e sustentável, não pode comprometer a vitalidade das pessoas, sua criatividade, seu desejo de realizar-se com base nas suas potencialidades, mas, sim, é necessário incentivá-las a se construírem como pessoas e profissionais. Portanto, a afirmativa' convida a refletir sobre o contexto atual das instituições/organizações de saúde e, em especial, do ambiente hospitalar, caracterizado e influenciado, principalmente, pela interconexão promovida pelos trabalhadores que formam redes ${ }^{15}$ vivas através da estruturação, organização e promoção do seu processo produtivo.

É com base nesse ponto de partida que se torna necessário o abandono da obediência incontestável nas instituições e, até mesmo, o uso da não contestação e a não força, porque esse novo posicionamento pode ser capaz de gerar um emergente modelo, mais satisfatório de significados, suscitar respostas e soluções no ambiente da enfermagem e dos demais trabalhadores no espaço hospitalar. Assim, ao promover a vitalidade da enfermagem e dos outros trabalhadores, fazendo com que estes se sintam parte do conjunto, responsáveis pela construção final dos processos, 0 resultado na área da saúde se torna mais significativo, pois incentiva o sentimento de pertencimento. ${ }^{12}$

Nesta reflexão, cabe salientar que todas as ações produzidas pela enfermagem e demais trabalhadores no ecossistema hospitalar deve ser empreendida com a finalidade de promover e manter a saúde, ou seja, a própria vida. Então, a enfermagem, ao abandonar o determinismo e a imposição de regras rígidas, predeterminadas, lineares nas ações exercidas de forma singular e coletiva nas instituições, e ao utilizar as características da sustentabilidade como a interdependência, reciclagem, parceria, flexibilidade e diversidade, constrói-se com maior autonomia no seu pensar e fazer.

Ressalta-se que a enfermagem, ao promover este pensamento e conseguir incorporar estas características do ser saudável e sustentável, no seu ambiente de trabalho, pode estar gerando uma condição de capacidade energética ao seu conjunto profissional e aos demais trabalhadores e, assim, representar os nós conectivos ${ }^{4}$ que tecem a rede ${ }^{15}$ viva da instituição/organização hospitalar, enquanto promove uma maneira particular/singular de ser e fazer enfermagem.

\section{CONSIDERAÇÕES FINAIS}

Ao discutir sobre o ambiente hospitalar na perspectiva ecossistema, emerge e torna visível uma teia de interconexões entre o trabalho/trabalhadores e o espaço/ Unidade Produtiva na qual atua. Para compreender a complexidade ${ }^{1,5,10}$ que esse espaço comporta, é necessário aprofundar 0 aprendizado para ampliar os conhecimentos, as tecnologias e habilidades e encontrar formas saudáveis e sustentáveis de produzir. A aprendizagem permanente no, pelo e para o trabalho no ambiente hospitalar pode desencadear um processo participativo entre as Unidades Produtivas e encontrar respostas mais satisfatórias às 
questões singulares e coletivas, construídas de maneira criativa e inovadora, pelo conjunto dos trabalhadores da instituição/organização.

A procura da mudança na lógica do modelo econômico existente - que busca acumulação de capital para o bem maior que é o de servir as pessoas e manter as instituições, vem ao encontro do modelo ecossistêmico. A meta desse modelo é garantir a eficiência produtiva, pois a sua conquista tem como significado maior o cuidado da manutenção da vida das pessoas e a sustentabilidade das instituições, comunidades e região, portanto torná-las mais saudáveis.

Os profissionais de enfermagem, ao compreender essa responsabilidade, podem se sentir instigados a buscar formas mais criativas e inovadoras de ser e estar nestes contextos. 0 momento de inovação precisa ser de coragem, lealdade, responsabilidade e ética para criar e recriar processos, através da complexidade da própria vida. Para produzir e viver bem, é necessário favorecer o equilíbrio da totalidade das dimensões do ser humano, biopsicossocial e espiritual e, consequentemente, do espaço em que vive.

Reitera-se que a enfermagem, ao utilizar as características sistêmicas da sustentabilidade, como a interdependência, parceria, flexibilidade, diversidade e reciclagem, no cotidiano do seu trabalho nas Unidades Produtivas, pode ser um agente de transformação do seu próprio ambiente. Essa transformação compreende um novo modo de produzir e viver através do trabalho, portanto um novo modus vivendi. 0 novo espaço deve primar pela amorosidade, solidariedade, compreensão, cooperação, criatividade e, especialmente, o produzir no coletivo através da aprendizagem permanente no, com e pelo trabalho. A vitalidade advinda desse novo modus vivendida enfermagem poderá influenciar todas as Unidades Produtivas a tornarem-se sistemas mais saudáveis e sustentáveis porque, pela interdependência sistêmica, a natureza do todo é sempre diferente da mera soma de suas partes, e o todo influencia nas partes e as partes sofrem influência do todo. ${ }^{1,5,6,9,15} \mathrm{~A}$ mudança encontra maior aceitação quanto maior for a significação desse processo para 0 trabalhador e, por isso, a estratégia a ser usada [...] "se resume em tornar o processo de mudança significativo para as pessoas desde o começo, em assegurar a participação delas e em proporcionar um ambiente em que a criatividade delas possa florescer "1:124. Essa é a forma que o ser humano necessita para sentir-se útil, prestigiado, bem-quisto porque assim a sua autoestima transporta-o para o sentir-se bem, sentir-se realizado, feliz. Esse novo modus vivendideve ser o resultado de uma nova forma relacional humana no, pelo e para o trabalho cuja base se encontra ancorada no conhecimento e na competência, e não mais na força, no poder econômico, porque toda riqueza é produto do pensamento criativo e do trabalho humano.

\section{REFERÊNCIAS}

1.Capra F. As conexões ocultas. São Paulo (SP): Cultrix; 2002.

2. Claval VP. A geografia cultural. $3^{\text {a }}$ ed. Florianópolis(SC): UFSC; 2007.

3. Diretrizes para a Gestão do Desenvolvimento Sustentável. [citado 09 fev 2009]. Disponível em: http://www.qsp.org.br/indice bs8900.shtml.

4. Siqueira HCH. As interconexões dos serviços no trabalho hospitalar: um novo modo de pensar e agir. [tese de doutorado]. Florianópolis (SC): Universidade Federal de Santa Catarina; 2001.

5. Capra F. 0 ponto de mutação. São Paulo (SP): Cultrix; 2004.

6. Rodrigues D, Arnold M. Sociedad y teoria de sistemas. Santiago (CL): Ed Universitária; 1991.

7.Bronfenbrenner U. A ecologia do desenvolvimento humano: experimentos naturais e planejados. São Paulo (SP): Armed, 2002.

8. Chiavenato I. Teoria geral da administração. $7^{\text {a }}$ ed. São Paulo (SP): Campus; 2004.

9. Luhmann N. Sistemas sociales: lineamentos para La Teoria Social. México( DF): Antropos; 2007.

10. LeffE. Saber ambiental: sustentabilidade, racionalidade, complexidade, poder. $2^{\mathrm{a}}$ ed. Petrópolis(RJ): Vozes; 2002.

11. Bertalanfly LV. Teoria geral dos sistemas. Petrópolis (RJ): Vozes; 2008.

12. Branden N. Auto-estima no trabalho: como pessoas confiantes e motivadas constroem organizações de alto desempenho. Rio de Janeiro (RJ): Campus; 1999.

13. Callenbach E, et al. Gerenciamento ecológico. São Paulo(SP): Cultrix; 1999.

14. Torres D, Leite JL, Moua MAV. Conflicto gerado por la designación de enfermeras para la direçon hospitalaria: uma visão periodística. Esc Anna Nery Rev Enferm 2008 mar; 12(1): 102-07.

15. Capra F. A teia da vida. $6^{a}$ ed. São Paulo (SP): Cultrix; 2001. 